\title{
EZI AGAMNIIHU NA MMEPE TỌRỌ ATỌ: NTỤLE USORO ỌCHỊCHỊ AGBỤRỤ ATỌ KACHA PỤTA IHE NA NA!̣IR!̣
}

\author{
Ifeyinwa Cordelia Isidienu* \\ http://dx.doi.org/10.4314/og.v15i1.3s
}

\section{Ụmịedemede}

Usoro ọchịchị dị nnukwu mkpa na ndụ agbụrụ ọ bụla. Ka agbụrụ si hazi usoro ọchịchị ha, tinyere ka ndị ọchịchị si achị na-eme ka obodo gaa n'ihu maọbụ laghachi azụ. Agbụrụ atọ kacha pụta ihe n'ala Naijirịa bụ, Igbo, Hausa na Yoruba nwere usoro ọchịchị ọdịnaala tupu a chịkọọ ha ọnụ dị ka otu obodo. Bido n'oge ahụ ruo taa, Naịjirịa enwebeghị udo tọrọ atọ. O bụ ọnọdụ dị etu a kpalitere ederede a n'itụle usoro agburư atọ ndị a si achị onwe ha n'otu n'otu nke mere na agbụrụ o bụla ka na-ahụta onwe ha dị ka otu agbụrụ dị iche n'agbụrụ ndị ọzọ. Nke a ga-enye aka iji tụpụta atụmatụ kacha mma ga-enyere ala anyị bụ Naịjirịa aka inweta udo na agamniihu bụ ịba. Iji nweta ebumnoobi a, e nyochara ederede dị iche iche ma gbasoo usoro akụkụkọala. Nchọpụta gosiri na agbụrụ Hausa na agbụrụ Yoruba bụcha ndị na-agbaso usoro ọchịchị ndị eze chi ha chibere ebe agbụrụ Igbo na-agbaso usoro ọchịchị ọha. N'otu aka ahụ, ala Naijirịa na-agbaso usoro ọchịchị onye kwuo uche ya, mana a chọpụtara na ha anaghị agbaso ya n’usoro ziri ezi. Ebe ọ dị etu a, ọ ga-aka mma ka e nye agbụrụ o bụla ikikere na ohere ịchị onwe ha, ka ọchịchị agbụrụ ọ bụla nwee ikikere karịa ọchịchị nke gọomentị etiti ka nnwere onwe, agamniihu, mmepe, udo na ihụnaanya wee dị. N'otu aka ahụ ịkwafu ọbara, ịla ndụ na akụnaụba n'iyi ga-abụzị akụkọ mgbe ochie.

Okwu Gbara Ọkpụrụkpụ: Agamniihu, Mmepe na Usoro Ọchịchị

\section{Abstract}

The method of leadership in the life of a nation is of great significance. This is because it is a strong determinant of a nation's progress or downfall. A case in point is the three major ethnic groups in Nigeria - Igbo, Yoruba and Hausa. The three had a uniọue, traditional leadership style prior to the 1914 amalgamation of northern and southern Nigeria. From then to now, Nigeria has not 
Isidienu: Ezi Agamniihu na Mmepe Tọrọ Atọ: Ntụle Usoro Ọchịchị Agbụrụ atọ ...

experienced lasting peace. It is against this backdrop that this research euplores the leaedership styles of the three ethnic groups in so far as their leadership styles have guaranteed their living together as one hitherto. This study is purposed to seek out the possibility of borrowing a leaf from the style of leadership of the three ethnic groups to see how they can help Nigeria to enjoy lasting peace, progress and development. The research work is historical in nature. With it, this study throws a search light into the leadership of the three ethnic groups to emulate the secrets of their success over the years. The study finds out that Hausa and Yoruba operate a monarchical style of leadership, whereas the Igbo have a republican kind of leadership. It is not democracy in the real sense of it. Yet, Nigeria, who claims to practice democracy, has nothing to show for it; not true democracy. In view of this, therefore, this study advocates for a decentralized government in Nigeria, in which the confederal ethnic groups will be given the power to govern themselves, and the power wielded by the centre will be less. The eupectation is that this governance type will help Nigeria to achieve eluding peace, progress and development.

Key Words: Progress, Development and Leadership

\section{Mkpọlite}

Agbụrụ atọ kacha pụta ihe n'ala Naijirịa nwere usoro ọchịchị ọdịnaala ha si na ya achịkọta onwe ha ọnụ; nke a na-enyere ha aka iji hụ na ịhụnaanya, mmepe, udo agamniihu na ezi mmekọrịta dị n’etiti onwe ha. Deji (2013) kwuru sị na tupu ndị bekee abata ala Naịjirịa na akụkọ agụguala kọwara n’ụzọ enweghị mgbagha, na e nwere usoro ọchịchị kwudosịị ike nke e deghị iwu ya n'akwụkwọ n'ala Naịjirịa. Usoro ọchịchị abụọ pụtara ihe n'agbụrụ atọ ndị a kacha pụta ihe n’ala Naijirịa bụ ọchịchị ndị eze na ọchịchị ọha. Ọchịchị ndị eze kacha pụta ihe n'ala Yoruba tụmadị n'agbụrụ ndị Hausa ebe eze ha na-enwe ikikere dị egwu. ọtụtụ oge ọ na-eji aka ike achị ọhanaeze. A bịa n'ala Igbo, ọ bụrịi eziokwu na e nwere obodo ụfọdụ ebe e nwere ọchịchị ndị eze chi ha chibere ma usoro ọchịchị kacha pụta ihe bụ ọchịchị ọha. Anozie (2003: 119) kwuru n’ụdị usoro ọchịchị a bụ "Ebe onye ọ bụla nwere ikike ikwupụta uche ya, itinye ọụ n'okwu o bụla n'enweghị mgbochi n'ụdị o bụla". Ihe ọ pụtara bụ n’usoro ọchịchị ndị Igbo rụtụrụ aka kpọmkwem n'usoro ọchịchị 
onye kwue uche ya; nke gosiri n'ụdịrị usoro ọchịchị a adịlarị n'ala Igbo tupu Naijirịa abụrụ otu nnukwu mba nke usoro ọchịchị ya hibere isi n'onye kwue uche ya.

Usoro ọchịchị onye kwue uche ya bụ nke magburu onwe ya, ma ka ihe si gbata kwụrụ n'ala Naịjirịa ugbu a, ọ bụghịzị ka akụilu si ada na ntị ka o si atọ. Ọ dịzị ka a ga-asị na ana-agbaso usoro ọchịchị aka ike. N'ihi nke a, a ga-eleba anya n'usoro ọchịchị onye kwue uche ya, usoro ọchịchị ọdịnaala ndị Hausa, Yoruba na nke ndị Igbo iji chọpụta usoro ọchịchị ga-aka mma iwepata n'ala Naịjịịa ka ọọdụ tigbue na zogbue wee belata.

\section{Nkowasị}

\section{Agamniihu}

Agamniihu bụ ịkwalite ogganiihu obodo site n'ikwupụta ọnọdụ na iwepụta atụmatụ ọhụrụ, echiche dị mma, tinyere ụzọ na nka dị iche iche aga-eji na-eme ihe ka obodo wee na-aga n'ihu.

\section{Mmepe}

Mmepe bụ usoro e si ahụ n'obodo na-emepe ma na-ebuwanye ibu. A ga-esite n'iji ụzọ dị mma duzie obodo ka mgbanwe wee bata. Ezeigbo (2013: 4) kọwara mmepe dị ka mgbe obodo na ndị bi n'ime ya ji nwanyọ nwanyọ na ebu iji kawanye mma, nwewanye agamiihu ga-eduga n'ikpughe ike mmepụta ndị mmadụ nọ n'obodo nwere n'otu n'otu. Ihe ndị na-eweta mmepe obodo bụ ụdịdị mmadụ e nwere n'obodo, tinyere akụ niile e ji gọzi obodo. Oge a ga-asi na mmepe abatala n'obodo bụ mgbe ndị mmadụ jizị ihe ndị ahụ e ji gozi obodo wee rụpụta ihe ga-enyere ndị mmadụ bị n’obodo ahụ aka na ndụ.

\section{Usoro Ọchịchị}

N'otu aka ahụ, usoro ọchịchị bụ ụzọ obodo si achọ mmepe, udo, agamniihu, ịdịnootu na ezi mmekọrịta n'etiti onwe ha site n'ịchịkọta onwe ha ọụ n'okpuru iwu nke ga na-ahazi akparamagwa onye o bụla nọ n'obodo ahụ. Onye ọ bụla ga na-ehubere iwu ahụ isi n'ihi na ọ bụ ya jikọrọ ha dum ọnu. A na-enwekwa ntaramaahụhụ dị̣rị onye o bụla dara iwu. 
Isidienu: Ezi Agamniihu na Mmepe Tọrọ Atọ: Ntụle Usoro Ọchịchị Agbụrụ atọ ...

\section{Usoro Ọchịchị Onye Kwue Uche Ya}

Ọchịchị onye kwue uche ya bụ usoro ọchịchị ebe ndị a na-achị ji aka ha ahọputa onye ha chọrọ ka o chịa ha. E si n'okwu bekee bụ "democracy" wee nweta okwu a bụ ọchịchị onye kwue uche ya; nke ntọala ya hibere isi n'okwu Giriiki bụ 'demos' - ọha na 'kratein' ịchị ọchịchị. Ihe nke a pụtara bụ usoro ọchịchị gọomentị ebe ọha ji aka ha achị onwe ha. Chidili (2012: 104) kwuru n'ụdị ọchịchị gọọmentị a bụ nke na-enye ọha ohere ka ha jiri aka ha họpụta onye ga-achị ha. Okodo (2006: 38) rụtụrụ aka n'ihe Nkwuaku (n.d: 13) kwuru, sị n'otu nkọwa na-ewu ewu e nyere maka ọchịchị onye kwue uche ya bụ nke onye mbụ chịị mba Amerịka bụ Abraham Lincolin nyere. ọ sịị na ọ bụ ọchịchị ọha, sitere n'aka ọha, a na-achị maka ọha. Ochịchị onye kwue uche ya bụ nke na-agbaso iwu ma naagbanwekwazị agbanwe. O bụkwaazị usoro ọchịchị nwere ike iwere ọnọdụ na mba ọ bụla dị ka ụdịdị ya siri dị. N'otu aka ahụ Salami (2006) mere ka o doo anya na-abịa n'ọchịchị onye kwue uche ya naekwesịị ime ka ike ọchịchị dị n'aka ndị dị iche iche. O kwuru naekwesighị ịmanye mmadụ ka o mee ihe abụghị uche ya. Dị ka o si kọwa, ọ sịị n’usoro ọchịchị a bụ nke na-eme ka mmadụ nwere onwe ya, nwee nkewa ike ọchịchị, bụrụ ọchịchị ọha tinyere ime ihe bụ ebumnobi ndị mmadụ. The nke a pụtara bụ na ọchịchị onye kwue uche ya abụghị ọchịchị otu onye kama mmadụ niile na-ejikọ ọnụ kwekọịta etu ha si chọọ ka e si mejupụta ebumnobi ha tinyere igbo mkpa na-emekpa ha ahụ site n'ịtụ arọ.

\section{Usoro Ọchịchị Ndị Hausa}

Agbụrụ Hausa na-agbaso usoro Emirate. Onye nọ n’isi ọchịchị bụ Emir. o bụ ya ka ikikere niile dị n'aka. o bụ ya na-eti iwu, ma manyekwa ndị o na-achị ka ha debe iwu ahụ. ọ ga-ahụ n’udo dị n'Emirate o na-achị ma hụkwa na ndị o na-achị na-agbaso usoro e kwuru a ga-esi na-eme ihe. Okodo (2016: 38 - 39) kwuru na Emir nwere ikike ikpebi okwu, ndị o na-achị anaghị agbagha okwu ya. Nke a mere o ji si na o nwere ike ọ bụrụ na enweghị usoro ọchịchị onye kwue uche ya n'agbụru ndị Hausa. Okafor na Emeka (2004: 87) kwuru n’usoro ọchịchị ndị Hausa bụ nke hibere isi n’ọchịchị ndị eze nwere nnukwu ikike n'ebe ndị ha na-achị nọ. Onyeeze batara n'ọchịchị ọhưrụ nwere ikike iwepụ ndị niile so eze ọ nọchiri anya n'ọchịchị ma jiri aka ya họrọ ndị ọ ga-etinye n'ọkwa ga na-ehubere ya isi. Ihe nke a gosiri bụ n'usoro ọchịchị ndị Hausa bụ nke anaghị 
Ogirisi: a new journal of African studies vol. 15s 2019

anabata ndụmọdụ site n'aka ndị a na-achị. O O bụ ihe ọ bụla eze kwuru ka a ga-eme n'agbanyeghị ndị otu ọụ ọ họpụtara tinye n’ọkwa dị iche iche dị ka:

1. Galadima:

Ọụ ya bụ ịhụ maka ego n’etu a ga-esi tinye ego ahụ n'ọrụ.

2. Waziri:

3. Maaji:

Ọrụ ya bụ ilekọta ndị niile ji ọkwa ọchịchị

4. Madawaki:

Ọ na-ahụ maka akụ

5. Sarkin pawa:

Onye ọchịagha ndị ami

6. Sarkin Ruwa:

Onyeisi ndị ogbu anụ

7. Dogari:

Onye ji okwa igbu azu n'osimmiri

8. Sarkin Fada:

Onyeisi ndị uweojii

n'obieze.

Ọ na-ahụ maka ndị niile na-arụ ọrụ

\section{Ndị ozọ gụnyere:}

a. Isi Ụlọ Ọrụ Kacha dị Elu: Ọ bụ Sokoto na Gwandu bụ isi ọnọdụ ndị Emir. Emir Sokoto na-achị alaeze ukwu keọwuwa anyanwụ ebe Emir Gwandu na-elekọta alaeze ukwu keọdịda anyanwụ.

b. Onye Nchịkwa Distrikt: E kewara Emirate o bụla na distrikt na distrikt ka o wee dị mfe n'ọchịchị. Emir na-eji aka ya ahọpụta onye nọ n'okwa nke a na-akpọ Hakimi ka ọ na-achị distrikt.

ch. Ndị Isi Ogbe: Hakimi ji aka ya ahọpụta ndị isi ogbe ndị ộụ ha bụ ịnakọta ụtụ isi.

d. Ndị Ọụ Omebeiwu: Iwu Islam bụ ya bụ iwu kacha dị elu n’Emirate o bụla. Ọ bụkwa Emir ka ime iwu dị n'aka, mana iwu ọ bụla o mere agaghị emegide iwu Islam.

e. Ụlọọụ Nchịkwa: Emir na-achị ọchịchị aka ike. Ikikere niile dị ya n'aka. ọ bụ eziokwu na o nwere ndị ndụmọọdụ mana ihe sọrọ ya ka o ga-eme.

f. Ọrụ Ikpe Ikpe: Iwu niile gbasatara ụlọikpe gbadoro ụkwụ na sharịa. ụlọikpe Emir bụ e jechaa ọ gwụ. Ndị ọkaikpe ka a naakpo Alkali.

g. Ọchịchị Etiti: Usoro ọchịchị bụ nke e wekọtara ọnụ n'etiti, ebe Emir bụ onye ji ikikere niile. Ọ bụ ọchịchị akaike.

\section{Njirimara Usoro Ọchịchị Ndị Hausa}

1. Ọ bụ nnọọ usoro ọchịchị ndị eze hibere isi n'iwu ederede ma bụrụkwa ọchịchị akaike.

2. A na-ana ụtụisi dị egwu. 
Isidienu: Ezi Agamniihu na Mmepe Tọrọ Atọ: Ntụle Usoro Ọchịchị Agbụrụ atọ ...

3. Ọ bụ ọchịchị etiti

4. E nweghị nkewa n'ebe ọchịchị na ekpemekpe dị.

5. Ndị a na-achị na-anọ n’okpuru iwu.

\section{Usoro Q̣chịchị Ndị Yoruba}

Usoro ọchịchị so n'otu ngalaba pụtara ihe n'omenala Yoruba. Usoro ọchịchị ha nwere ka o si gbanyetụ ụkwụ n'ọchịchị onye kwue uche ya n'ihi na ndị a na-achị nwere ka ha si esonye n'ọchịchị. Ha na-eme nke a site n'inwe ndị ọ bụ orụ ha ịhọpụta onye ọchịchị. Ha naelerukwa anya ka onye ọchịchị si achị ma na-atụle usoro ọchịchị ya. Salami (2006) kwuru n'usoro ọchịchị ndị Yoruba bụ nke na-anabata ndị a na-achị isonye n'ọchịọchị n'ihi na o nwere ụzọ dị iche iche e si ewebata ndị dị iche iche na anọchite anya ọhanaeze ma mee ka ahụ na ndị na-achị achị na emejupụtara ebumnobi ndị ha na-achị. O kwuru na-abịa n'usoro ọchịchị ọdịnala Yoruba n'eze obodo (Ilu) bụ ọba. Baale bụrụ onye na-achị n’ogbe dị iche iche. Onyeisi n'ezinaụlọ ka a maara dị ka Olori Ile. Okodo (2006) kwuru na a na-enwe ọba na ngalaba niile. ọ bụkwazi ọba ka ha na-elegara anya ka o na-agbaziri ha. Iwepụta onye ga-anọ n'ọkwa n'ogogo ọba bụ site n'ime nhọpụta. Mgbe ụfọdụ, ọ bụrụ onye kacha buru okenye ma ọ bụ site n'agbụrụ ndị na-abụ eze. N'ezie ihọpụta onye ga-abụ ọba ọtụtụ oge na-abụkarị n’agbụrụ ndị na-abụ eze site n'ọmụmụ.

N’ịga n'ihu, a bịa n'ọyọ, Alaafin na-abụ onyeisi. Deji (2013) kwuru na Alaafin keọyọ n’oge ahụ bụ ya ji ikike ọchịchị bịakwa buru onyeisi ndị ọchịagha, ebe Ooni kelfe bụ onyeisi ekpemekpe ala Yoruba niile. Alaafin ọ bụla ga-esiriri n'agbụrụ ọranmiya, nke bụ eze mbụ e nwere n'ọỵ. Ka ọnọdụ ya si dị site n'ọmụmụ, ọ nwere ikike n'ebe mmadụ niile nọ n'obodo ya dị. Ha kwenyere na Chukwu wesịara o were. Mmadụ apụghị ịgbagha ya okwu. A naakwanyekwara ya ugwu na nsọpụrụ dị egwu. Okodo (2006) kwuru na ọ bụ ọba na-eduzi omume ọhanaeze. Ọ siri na ndị Yoruba ka naasọpụrụ ọba rue taa nke na e nwee nghọtaghie n'etiti ọba na gọvọnọ na-achị Steeti na ha na-akwụnyere ọba. Ihe nke a gosiri bụ na ha e jighị ọba egwu egwu, ọ bụrụzịa na ọ bụ ezigbo mmadụ ịmara na ha ga na-efe ya nru. N'aka nke ọzọ, ọ bụrụ na ọba abụghị ezigbo mmadụ ọ bưrụ na ọ hapụ ime ihe a tụrụ anya n'aka ya dị ka ichekwa omenala na ihu maka ọịmma nke obodo na ọanaeze, bidozie chịwa ọchịchị nchigbu, ọhanaeze agaghị anabata ya. 
Ndị ọ bụ ợu ha ịhọpụta ọba, bụ ọyọ -Mesi na mmadụ asaa ndị a: Ba, orun, Agbaakin, amụ, Alapini, Laguna, Akiniku na Ashipa. Tupu a họpụta onye ga-abụ ọba, ha ga-ebu ụzọ gaa n'afa site n'ijụ Ifa ase. Salami (2006) siri na-abịa n'ala Yoruba na o bụ site n'ihe Ifa kwuru na-enyere mmadụ asaa ahụ na-ahọputa onye ga-abụ eze aka. Dị ka anyị si kwu na mbụ, ọba-bidozie imekpa ndị ọ na-achị ahụ, ọọ-Mesi, onye ọnọdụ ya dịkwa ọkpụtọrọkpu ka nke ọba nwere ikikere ilebara ya anya n'usoro ọchịchị ya. Ọba jụ ịnabata ndụmọọdụ na ịhazigharị akparamagwa ya ka omenala si dị, a ga-ebunye ya obele ma o bụ nye ya akwa ichooku. Ihe ndị a gosiri na ọhanaeze ajụla ya. o ga-esiriri n'ọkwa ahụ rituo site n'iga kwugbue onwe ya, mana n’eziokwu, a naghị ahụkebe ụdị ọnọdụ a.

\section{Ndị Orụ Omebeiwu:}

Ọba na-ajụta Mesi ihe niile gbasara usoro iwu eji achịkwa obodo na ngalaba ha na-achị. N'otu aka ahụ, imebe iwu dị ọba na ndị isi Chiifu n'aka. Imebe iwu ọhụ, ịka ụtụ tinyere ụzọ e si bue agha megide ndị iro dị ha n'aka. ọ bụrụ na ndị isi chiifu ya emebe iwu nke ya onwe ya nabatara ndị ọụ ekwe ga-akụ ekwe n'obodo iji gwa ọha obodo maka iwu ọhụụ ahụ.

\section{Ụlọ Ọụ Nchịkwa:}

Ọba anaghị achị ọchịchị akaike. oyọ Mesi na-anọchite anya obodo niile dị na ngalaba ya ma na-ahụkwa maka ọdịmma ha. Kansulu ya na-eleba anya n'ihe niile ọba na-eme iji hụ na ọ naghị achị ọchịchị nchịgbu. Onye ọ bụla na Kansulu mmadụ asaa ahụ nwere ọrụ pụrụ iche ha na-arụ n'obodo. Ọba ga na-ajụtazi Mesi ka ọchịchị si aga na ngalaba ọ na-achị. Ọ bụ ndị Chiifu, odibo, ndị nwunye tinyere ndị ohu na-abụ ụzọ ọba na ndị ọ na-achị si ezikọrịta ozi.

\section{Orụ Ikpe Ikpe:}

ọba na-ajụta Mesi ihe niile gbasara ikpe tụmadị ikpe ikpe nkwụmọọtọ na ngalaba ha na-achị. Mmadụ asaa ahụ ọrụ ha bụ ịhọputa onye eze ga na-anọrịị n'ọgbakọ ụlọ ikpe keeze. Ogboni bụkwa otu nzuzo siri nnukwu ike na-esonyekwa n'ihe gbasara ikpe ikpe.

N'aka nke ọzọ e nwee esemokwu, ndị isi ezinaụlọ, ụmụnna na ndị okenye ga-abịa dozie okwu ahụ. Onye ikpe mara arịo mgbaghara, ọ jụ e nwere ike ịmapụ ya. A ga-ewegara ọba na ndị 
Isidienu: Ezi Agamniihu na Mmepe Tọrọ Atọ: Ntụle Usoro Ọchịchị Agbụrụ atọ ...

Chiifu ya ikpe ọ bụla siri ezigbo ike, mkpebi ha bụ e jechaa ọgwụ. E nwere ike ịda onye dara iwu nha; o bụrụ onye mere nnukwu ajọ ihe e nwere ike ịma ya ikpe ọnwụ ma ọ bụ ichupu ya n’obodo.

\section{Njirimara Ochịchị Ndị Yoruba}

1. Ọ bụ usoro ọchịchị ndị eze hibere isi n'iwu.

2. E nweghị usoro ọ bụla ha si anakọ ndị a na-achị ụtụ isi kama ha na-efe ndị eze nru.

3. E nweghị nkewa n'ebe ọchịchị na ekpemekpe dị.

4. A na-elebara eze anya n'ọchịchị.

\section{Usoro Ọchịchị Ndị Igbo}

Bido n'oge ochie wee rue taa, ọ dịghị mgbe ndị Igbo niile chịkọtara onwe ha ọu iji nọrọ n'okpuru otu onye ọchịchị dị ka otu nnukwu ebo. Ndị Igbo na-achị onwe ha n'obodo n'obodo. Anọzie (2013: 119) kwuru na ndị "Igbo enweghị ụdị ọchịchị ebe naanị otu onye nwere ike na-achị nnukwu ọha obodo". Usoro ọchịchị ndị Igbo bụ nke na-eme ka onụ na-eru onye ọ bụla.

Usoro ọchịchị abụọ pụtara ihe n’ala Igbo n’oge ochie bụ ọchịchị ndị eze na ọchịchị ọha. Ọchịchị eze ezughị ala Igbo niile ọnụ; obodo ọ putara ihe n'oge ochie bụ, Arochukwu, Onicha, Ugwuta na Nri. A na-ahụta ha dị ka ndị eze chi ha chibere nke pụtara na ọ bụ Chineke mere ha eze ma mee ka ọchịchị ha dị ọkpụtọrọkụ. Ndị Igbo naezipụta echiche a n'okwu ọnụ dị ka chi na-eme eze, a na-azọ eze azọ, chi nyelu ugo. Ọchịchị ha anaghị abụ ọchịchị aka ike n'ihi na e nwere ndị nze na ọzọ, tinyere ndị nnọchite anya ogbe na-esonyere ha n’ọchịchị.

Usoro ọchịchị oha bụ nke zuru ala Igbo niile ọụ. Nke a bụ ebe ikike ọchịchị dị ndị a na-achị n'aka. Ekwealor (1998: 63) kwuru na ndị Igbo "Haziri ọchịchị obodo n’ụzọ ọnụ ga na-eru onye ọ bụla n'okwu. A na-akpọ ogbakọ obodo ebe a na-anọ were wepụta atụmatụ dị iche iche a na-agbaso". Atụmatụ ọ bụla e wepụtara bụ ihe ọha kwekọrịtara. Nke a mere n'usoro ọchịchị ndị Igbo anaghị abụ ọchịchị nchigbu.

N'ala Igbo dum ọchịchị na-amalite n'ezinaụlọ, si na ya baa n’ụmụnna, ogbe na obodo. E nwekwara ewumewu ọchịchị ndị ọzọ dị ka otu ọgbọ, ndị chiri echichi, otu nzuzo dị ka mmanwụ, ụmụada, iyomdi dgz. na-esonyekwa n'ọchịchị obodo. A bịa n'ọchịchị ezinalụọ nna bụ onyeisi. Isidienu (2016: 84) kwuru na ọ bụ eziokwu 
na nna bụ onyeisi ezinaụlọ, mana ọ gaghị e ji aka ike wee na-achị. A na-akpọ nzukọ ezinaụlọ ebe onye ọ bụla ga-anọ kwekọịta n'ihe ọ bụla a chọrọ ime. ọụ onyeisi ezinaụlọ gụnyere; ọchịchị, ofufe, ilekọta akụnaụba na ịhụ na ndị ezinaụlọ ya na-enwe ezi mmekọịta. Ihe pụtara ihe bụ na, ọ bụ n'ezinaụlọ ka ọchịchị na-amalite n'ala Igbo. o bụrụ na nna anwụa, ọchịchị na-aba n'aka diọkpara ezinaụlọ, okwu ọ bụla karịị ha n'ezinaụlọ ka ọ ga-ewepụ n'ọgbakọ ụmụnna. Ezinaụlọ dị iche iche na-emebe ụmụnna onye kasị bụrụ okenye naabụ onyeisi ụmụnna. N'otu aka ahụ ọ ga-eji ịtụ aro ma hụ na ndị ụmunna na-ekwekọịta tupu e mee ihe o bụla. Ha na-ekpeziri onwe ha ikpe o bụla daputara n'ụmụnna. ụmụnna o bụla na-enwekwaa iwu na-achị ha. ọchịchị sizie n'ụmụnna, ọ banye n’ogbe. ụmụnna dị iche iche na-emebe ogbe. Ekwealor (1998: 65) kwuru "n'ogbe o bụla, a na-enwe oggbakọ ụmụnwoke na ọgbakọ ndị inyomdi, ebe ha na-anọ ewepụta atụmatụ dị iche iche gbasara ọdịmma na ọaniihu ogbe ha”. Akinyele (1997: 281) kwadoro echiche a mgbe o kwuru si na-abịa n'ọgbakọ ogbe na onye ọ bụla nwere ikike ikwu okwu, ọzọ, onye ọ bụla ga-ekwekọịtakwa n'atụmatụ ọ bụla a tụpụtara tupu e were ya tinye n'orụ. Ogbe dị iche iche na-emebe obodo. ọ bụkwa oke na orụ dịirị ogbe o bụla ịhọpụta ndị ga na-anọchite anya ha n'obodo. Onyeisi obodo na-abụ onye kasị bưrụ okenye n'obodo ma ọ bụ ụmụnna ma ọ bụ ogbe busi ụzọ biri n'obodo ahụ. Ihe ọzọ dị mkpa bụ na a bịa n'ala Igbo ndị okenye na ndị chiri echichi kasị dị elu dị ka ozọ na-esonye n'ọchịchị obodo. Isidienu (2016: 88) kwuru na ọ bụ ndị isi ogbe dị iche iche na ndị chiri ọzọ na-atụpụta atụmatụ e ji achị obodo.

N'ịga n'ihu, o bưrụ obodo e nwere eze ala; ị mara na eze ala ga na-ahụ maka ofufe, ebe onyeisi obodo na ndị otu orụ ya ga na-ahụ maka ọchịchị obodo. Nke a gosiri n'ọchịchị n'ala Igbo e nweghị mgbe o ji adị n'aka otu onye. Ekwealor (1998) kọwapụtara na "Ọ bụ eze na ndị ichie ya na-ewepụta atụmatu e ji achị obodo. ọ bụkwa site n’ogbe dị iche iche ka e si ewepụta ndị ichie ndị a. Nke a pụtara na ogbe o bụla nwere onye na-anọchite anya ya n'ebe a na-eweputa atụmatụ e ji achị obodo". N'ezie ndị nnọchite anya ogbe ọ bụla naahụkwa na oke ha efughị mgbe o bụla a na-atụpụta atụmatụ. Ndị niile nọ n'otu ọgbakọ ahụ na-ahụkwa n'atụmatụ ha bụ nke ga-eweta udo, agamniihu, nchekwa na idinootu nye ọha obodo. o dịgị onye ma ọ bụ ogbe ọ bụla a ga-eme ihe na mmegide. Ndị Igbo tụrụ n’ilu si 
Isidienu: Ezi Agamniihu na Mmepe Tọrọ Atọ: Ntụle Usoro Ọchịchị Agbụrụ atọ ...

na "e mee nwata ka e mere ibe ya obi adị ya mma. ụdị echiche dị etu a na-eme ka ịdịnootu na agamniihu tọrọ atọ na-adị n’obodo.

\section{Ụfọdụ Ewumewu Ọchịchị ndị ọzọ e nwere n’ala Igbo gụnyere: Otu Ogbọ:}

Ndị otu ọgbọ bụ ndị a mụrụ otu oge. Ựfọdụ nwere ike jiri afọ abụọ ma o bụ karịa tọo ibe ha. Ha so na ndị ọchịchị obodo dị n'aka. Ha na-enye aka ahụ na udo dị n'obodo. Dị ka Ekwealor (1998: 67) si kwu "Oge ụfọdụ, ọ bụ otu ọgbọ ụmụokorobịa na-ahụ na iwu ndị okenye tiri dị ire site n'iji ụzọ dị iche iche dị ka mmanwụ wee buso ndị dara iwu ndị a agha. Site n'ụzọ dị otu a, otu ọgbọ na-eme ka ime mpụ belata n'obodo. Otu oggbọ bara nnukwu uru n'ọchịchị obodo. Ha na-arụkwa orụ dị iche iche na-eweta mmepe n'obodo ma nyekwa aka na-ahụ na a na-enwe ezi mmekorịta n'etiti ọhanaeze. Ndị otu ọgọ nọkwaazị ọdụ ka ndị amị n'ihi na ha na-ebu agha megide ndị ọ bụla bịara ibuso obodo ha agha, tụmadị otu ọgbọ ụmụ okorobịa.

\section{Ụmụada (ụmụọkpụ):}

ụmụọkpụ bụ otu ụmụnwaanyị amụrụ n'obodo lụrụ dị n'obodo ha ma ọ bụ n'obodo ọzọ. Ha nwere ikike dị egwu. A na-enye ha ugwu ma nsọpưrụ n'ezinaụlọ ha n'ihi ộu pưrụ iche ha na-arụ. Nke kacha pụta ihe bụ idozi esemokwu n'ezinaụlọ nna ha ya na obodo ha. Ha na-esi n'ụzọ dị etu a, mee ka udo na agamniihu na-achị na-ebe a mụrụ ha. Otu ụmụọkpụ na-enwekwa iwu na-achịkwa akparamagwa ndị otu ha. Okodo (2016: 43) kwuru na ndị na-achịkwa ha na-agbaso usoro ọchịchị onye kwue uche ya. Ha na-ege ntị na-atụmatụ ndị otu ha, ma were ihe ọha kpebiri tinye n'ọrụ.

\section{Inyomdi:}

Ha bụ ụmụnwaanyị a na-alụ n'ezinaụlọ ma ọ bụ n'obodo. Ha naenwe iwu na achị ha. Ha na-enwe ọgbakọ kwa mgbe kwa mgbe, ebe ha na-anọ tụpụta arọ ma kwekọịta n'ihe ha ga-eme. Ha na-edozi esemokwu n'etiti onwe ha, ma na-enyekwa aka ịhụ na udo na ịdịnootu dị n'ezinaụlọ ha, ya na obodo ha. Ha na-abagidekwa ọrụ mmepe dị iche iche nke na-enye aka eweta agamniihu n'obodo. 


\section{Ụlọorụ Nchịkwa:}

Ndị isi ezinaụlọ, ụmụnna, ogbe tinyere ndị okenye, ndị otu ọgbọ, ndị chiri echichi dgz na-atu arọ ka obodo ga-esi na-aga n'ihu. Ha naakpa ka ihe ga-esi na-aga n’obodo mgbe ọ bụla ha gbakọrọ.

\section{Orụ Omebeiwu:}

Ọha ji aka ha emebe iwu ha ga na-agbaso ndị okenye na-esokwa emebe iwu e ji achị obodo. Ndị otu ogbọ nwekwara ike mebe iwu. Ndị okenye na-anabatakwa iwu ndị otu ogbọ tiri. Otu ndị ọzọ dị ka ụmụada, uyomdi na-emebekwa iwu ndị otu ha na-agbaso.

\section{Ọụ İke Ikpe:}

Onyeisi ezinaụlọ ọ bụla na-edozi esemokwu dapụtara n'ezinaụlọ. Ndị okenye, onyeisi ụmụnna, ndị nnọchịte ogbe ma obodo, ndị chiri echichi, otu ọgbọ ụmụọkpụ dgz. na-enyekwa aka n’idozi esemookwu.

\section{Njirimara Usoro Ọchịchị Ndị Igbo}

1. Ọchịchị ọha. A naghị akwanye mmadụ akwanye ka o mee ihe.

2. Onye ọ bụla bụ eze na be ya. N'ezinaụlọ nwoke ọ bụla na-achị be ya.

3. A naghị ana ụtụ isi ma ọ bụ manye mmadụ amanye ka o nye eze ihe. Ihe onye chọrọ ka o ga-enye eze.

4. Ọchịchị anaghị adị n’aka otu onye. ọnụ na-eru onye ọ bụla n'okwu.

5. E nweghị ụzọ pụrụ iche ma ọ bụ iwu e ji ana onye ọ bụla ụtụ isi. Ihe a ga-arụ dapụta e nwere ike ịka ụtụ mgbe ụfọdụ o bụrụ nnukwu azụ kpata nnukwu nkụ, obere azụ kpata obere nkụ.

\section{Usoro Ochịchị Nigeria}

Aha a bụ Naijirịa bụ ndị ọcha mbịarachịwa sị mba Britain nyere ya agbưrụ dịbu iche iche nọọọ onwe ha, bido n'agbata narịafọ iri na iteghete. Ka o ruru n'afọ 1914 ha jikọtara Ndịda anyanwụ Naijirịa na mpaghara Ugwu Naijirịa ọnụ. Ndị ọcha mbịarachịwa gbasoro usoro ochịchị 'indirect rule' site n'ịhọputa ndị Eze ọdịnaala a kpọo "Warrant Chiifu" ha ji wee na-achị ndị bi na mpaghara ndịda anyanwụ Naijirịa tụmadị n’ala Igbo. Ekwealor (1998: 17) kwuru n'usoro "Ọchịchị ha wubere bụ nke a ga-eme site n'ịhakobe eze ọdịnaala, we na-agwa ya ihe ha chọrọ ka e mee". Ọ gakwara n'ihu 
Isidienu: Ezi Agamniihu na Mmepe Tọrọ Atọ: Ntụle Usoro Ọchịchị Agbụrụ atọ ...

kwue "n’ikike ndị Bekee nyere ndị warrant chiifu dị egwu. Ọ bụghị naanị na ha bụ ndị ọchịchị, kama ha sokwa ekpe ikpe n'ụlọikpe nke Bekee wubere na mpaghara ala Igbo dị iche iche". N'ihi na ndị mpaghara ndị ọzọ nọ n’ala Naijirịa nwere eze ọdịnaala; ndị Bekee jizi ndị chiifu ndị a were na-achị ndị bi na ndịda anyanwụ Naijirịa.

Naijirịa nwezịirị onwe ya n'afọ 1960. O ruo n'agbata afọ 1967 ruo 1970 a lụa agha "Civil War" malite n’oge ahụ, e nweghị usoro ọchịchị doro anya n'ihi ndagharị usoro ọchịchị e nwere oge ahụ naadagharị, mgbe ụfọdụ e nwee ọchịchị onye kwue uche ya, mgbe ụfọdụ e nwekwa ọchịchị aka ike. Onọdụ a digidere ruo n’afọ 1999 oge Naijirịa jizị nwee usoro ọchịchị onye kwue uche ya nke nwere ngalaba atọ pụtara ihe. Ngalaba ndị a gụnyere: ụlọọrụ nchịkwa, ụlọọrụ omebeiwu na ụlọọrụ ikpe.

\section{Ụlọọrụ Nchịkwa:}

E nwere otu onye bụ onyeisi ala na-achị ala Naijirịa dum. A naahọputa ya site n'ịtụ vootu na mpaghara ala Naijirịa dị iche iche. Emeka (2004: 61) kwuru na iyi ọụ e duru ya na-ekwu na ọ bụ iwu na ọ ga-abụ onye odibo, onye nchekwa ma bụrụkwa onye ga naakwalite mpaghara ala Naijirịa niile. O ga-abụkwa akara ịdịnootu nye mmadụ niile. Dị ka iwu ala Naịjirịa si dị e nwekwara ndị ọchịchị na steeti dị iche iche, nwekwa n'okpuru ọchịchị dị iche iche iji mee ka onye ọ bụla keta oke n'ọchịchị onye kwue uche ya. A na-ahụtazị onye ọ bụla dị ka ndị sitere n'otu mba, n'agbanyeghị agbụrụ onye si pụta.

\section{Ụlọọụ Omebeiwu:}

A na-ahọpụta ndị omebeiwu site n'ịtụ vootu. Ọ bụkwa ha na-emebe iwu nke a tụrụ anya n'iwu ahụ ga-abụ maka ọịmma mmadụ niile. O bụ kwarịi eziokwu na ha si na mpaghara dị iche iche wee pụta mana ha agaghị ebu ya n'uche mgbe ha na-eme iwu kama ha ga naeche maka mmadụ niile nọ n'obodo.

\section{Ụlọọụ Ikpe:}

Ikpe ziri ezi bụ ihe nrite dịiri ọhanaeze. Ndị ọkaikpe na-anụkwa iyi inye ọhanaeze ikpe ziri ezi n'akpaghị oke ma o bụ ijụ mpaghara onye si pụta. Mba niile dị n’ụwa na-elegara ụlọọrụ na-ahụ maka ikpe anya inye ọhanaeze na akụnaụba ha ezi nchekwa tọrọ atọ. A na-esite n'ụzọ dị etu a nwee agamniihu, udo na mmepe dị egwu n'obodo. 


\section{Inweta Mmepe na Agamniihu Tọrọ Atọ na Naijiirịa}

Agbụrụ e nwere n'ala Naịjirịa ga-eru narị abụọ na iri ise. Asụsụ dị iche iche a na-asụ na Naịjirịa ga-erukwa narị ise n'ọnụọgụgụ. A gaasị na agbụrụ atọ kacha buo ibu bụ Igbo, Hausa na Yoruba. Nchọpụta na-egosi na site n'oge ahụ e jikọrọ agbụrụ dị iche iche kwụụrụ onwe ha ọnụ, ha bụrụzịa otu nnukwu mba a maara dị ka Naịjirịa, were ruo taa, ọhanaeze mejupụtara ala Naịirịa aghọtabeghị onwe ha, nke mere na tigbue, zogbue, ila ndụ na akụnaụba n'iyi nke na-eweta ndaghachị azụ na-adapụta kwa mgbe kwa mgbe. Ọtụtụ oge ndị mmadụ na-achị uche n'aka n'ihi amaghị ihe echi ga eweta. Okodo (2006: 37) kwadoro echiche a site n'ịrụtụ aka n'ihe Ojiakor (2003: 178) na Unachukwu (2003: 143) kwuru gbasara ọchịchị onye kwue uche ya e nwere na Naijirịa; ha sịrị na usoro ọchịchị onye kwue uche ya abụrụla ihe mara afọ n'ala na Naijirịa; ebe iri ngarị, enweghị nsọpưrụ n'iwu na mpụ dị iche iche mere ka a kwatue usoro ọchịchị onye kwue uche ya kembụ ya n'ala Naịjirịa. Nsogbu dị n'ala Naịjirịa n’oge dị ugbu a dị ka, ịkwafu ọbara, mwakpa, idina ụmụnwaanyị n'ike, ọha ịnọ n'agbụ, nkewa, mgba okpuru tinyere arụrụala dị iche iche mere ka mmepe na agamniihu bụrụ ihe naalaghachi azụ n'ala Naịjirịa. Ọnọdụ dị etu a jọrọ nnukwu njọ ma dị mkpa na a kwọrọ mmiri ugbu a ọ ka nọ n'obo ọkpa. Ndị Igbo tụrụ ilu sị na e mee ngwa ngwa e meghara ọdachị.

N’ịga n'ihu, e nwere ike ịsị na ajọ ọnọdụ Naijirịa nọ na ya ugbua bụ njikọ ahụ ejikọrọ agbụrụ dị iche iche nọọrọ onwe ha ọnụ butere ya. Crowder kwuru (1978: 11) n'obodo o bụla keakamere ma ọ bụ e sitere n’ụzọ wuruwuru were kepụta dị ka ala Naijirịa, etu ọ dị, njikọta ọnụ bịara na mberede nke gụnyere obosara otu igwe ndị mmadụ dị iche iche ndị British kepụtara, ebe ndị bi ebe ahụ n'onwe ha na-enwe obi abụọ ma ndọrọndọrọ ọchịchị a ga-akwụdowu. Ihe nke a gosiri bụ na ọ bụ ndị Bekee kepụtara ala a bụ Naijirịa site n'ịchịkọta obodo dị iche iche enweghị otu asụsụ, nkwenye, ọdịnaala, omenala tinyere otu usoro ọchịchị. ọ dịghị ihe ọ bụla jikọrọ ha ọnụ na mbụ. Ọ dịghịkwa mgbe agbụrụ ndị a bịakọtara ọnụ, imekọrịta n’ụdị ọ bụla iji bụrụ otu. Ọ bụ nke a mere Tamuno (1970: 566) jiri si na ọ dị mfe ikepụta obodo Naịjirịa mana iwekọta ndị mmadụ bi na ya ọnụ ka ha bụrụ otu mba hịara nnukwu ahụ. Ka o sila dị a gbaala ọtụtụ mbọ ime ka ọhanaeze bi n'ala Naịjirịa jiri otu mmụọ na-eme ihe, na-ahụta onwe ha dị ka otu mba enweghị ịkpa oke. N'agbata afọ 
Isidienu: Ezi Agamniihu na Mmepe Tọrọ Atọ: Ntụle Usoro Ọchịchị Agbụrụ atọ ...

1992 ruo 1993 ka ọhanaeze tiri mkpu n’ọgbakọ ala Naịjirịa e nwere, si ka a kpaa arọ inwe obodo Naịjirịa ọhụu site n'iwebata ụkpụrụ naebe mpaghara ibu onyeisi ala Naijirịa dị. Nke ga-eme na ịbụ onye isi ala ga na-erute agbụrụ ọ bụla dị n'ala Naịjirịa. Ka ọ ga-abụ otu agbụrụ chịa n'otu oge emere nhọpụta, agbụrụ ọọ a chịakwa n’oge ozọ. A tụrụ anya na nke a ga-eme ka mmepe rute agbụrụ niile, nke ga-eweta ezi agamniihu, were rue taa, atụmatụ a dara mmiri.

Atụmatụ ndị ọzọ e hibere iji hụ na agamniihu na mmepe tọrọ atọ dị n’ala Naịjirịa gụnyere iguzobe agwa gọọmentị keetiti (federal character) ơrụ ha bụ ịhụ na ekere ihe niile e nwekọrọ ọnụ na-ejighị mmegbu. Dị ka Isidienu (2013) si kọwapụta n'iguzobe otu a na steeti niile dị na Naijirịa e meela ka e wee ọtụtụ ndị mmadụ n'ọrụ Bekee kegọomenti etiti nke mere ka ndị si agbụrụ dị iche iche bịakọta ọnụ, mekọịta, chigharịkọta uche ma na-emekọ ihe onụ. N'otu aka ahụ, gọomenti etiti guzobekwara otu ndị ntọrọbịa ji otu afọ efe ala Naijirịa (National Youth Service Scheme) nke a ga-eme ka ha fee ala nna ha na steeti abụghị nke ha were nọkọọ, mekọịta n'ụzọ dị iche iche; ebe omenala, asụsụ ga-ejekọịta; ụzọ ọzọ bụ nhibe e hibere, ụlọakwụkwọ ndịnootu, ebe nwata akwụkwọ nwere ohere ịbanye ịgụ akwụkwọ n’ụzọ kwesịị ekwesi. Ekpemekpe bụkwa ụzọ ọzọ atụputara a ga-esi nweta ezi mmepe na agamniihu site n'ihu naamanyeghị onye ọ bụla amanye n’usoro ekpemekpe o bụla. Onye ọ bụla nwere ikike ịnọ n'usoro ekpemekpe o chọrọ ma nwee ikike ikpere chi ọ bụla ọ chọrọ. Isidienu (2013: 202) kwadoro echiche a mgbe o kwuru n'iwu ọzọ dị nnukwu mkpa e tiri n'ala Naịjirịa bụ ikewapụ ekpemekpe n'usoro ọchịchị. Ihe o pụtara bụ na usoro ọchịchị e nwere n’ala Naịjirịa a gaghị na-agbaso nzọ ụkwụ ekpemekpe o bụla. N'ihi nke a, e nwere nnwere onwe n'usoro ekpemekpe ọ bụla onye ọ bụla chọrọ isonye na ya.

Atụmatụ ndị a bụ nke mara nnukwu mma, mana n'aka nke ọzọ, ọ dịghị mgbe ha gboro mkpa cheere ala anyị bụ Naịjirịa aka mgba n'ihu kpamkpam. A kpọo ya ọchịchị onye kwue uche ya, mana ọ bụghị etu akụilu si ada na ntị ka o si atọ. E nwere ike isi na ọ tụgharịị bụrụ ọchịchị aka ike na ọchịchị nchigu. Mgbe ụfọdụ onye kwue o fue n'otu ntabi anya. O bụghị ihe ekwe na-akụ ka a na-agba. E nwerekwara ike isi na ọ dịghị onye maara ebumnobi ndị ọchịchị na mpaghara dị iche iche.

Ọchịchị onye kwue uche ya abụghị ọchịchị otu onye kama a na-abịakọtaọnụ n'ogo dị iche iche maka agamniihu obodo. ọ bụ 
ọọdụ onye emegbula ibe ya. A bịa na Naịjirịa e kesara ọchịchị ka ọ dị ndị a na-achị nso. Ochịchị ime ime obodo na-elekọta ndị niile bi n'ime obodo dị iche iche na-ahụ maka mkpa ha ma were ya wegara ọchịchị steeti. Ha na-anọchitekwa anya ha n'ogo steeti. ọchịchị steeti na-anọchitekwa anya ọhanaeze steeti ha na gọomentị etiti. Ọchịchị etiti na-anọchite ọhanaeze Naijjirịa niile ma na-ahụ na ihe na-aga n'anya ya. E nwere ike isi na ọchịchị onye kwue uche ya e nwere ugbu a, a naghị emejupụta ebumnobi ọhanaeze n'ihi na ọ na-ebute ọbaghara na ndị kwe na ndị ekweghị n'ebe dị iche iche.

o bưrụ na-elebaa anya nke ọma n'usoro ọchịchị agbưrụ atọ kacha pụta ihe n'ala Naịjirịa si achị onwe ha, a ga-achọpụta na ọ bụ usoro dị ọkpụtọrọkpụ. Usoro a baara ọhanaeze nwe ya uru. ọ bụ usoro ọchịchị na-egboro ha mkpa dịirị ha. ọ bụ nke a mere na agbụrụ ndị a ka jikọkwara ọnụ bụrụ otu na-ebi n'udo.

Ndị Hausa nọ n’okpuru Emir. Ọ bụ ya ka ikikere ọchịchị niile dị n’aka. Okwu ya bụ e jesịa ọ gwụ. ọchịchị ya dị ndị ọ na-achị mma n'ahụ. Ọ dịbeghị mgbe ọ bụla ha nupuru isi n'ọchịchị Emir. Ihe o pụtara bụ na ha nabatara usoro ọchịchị ya.

Ndị Yoruba nwekwara ọba dị ka eze ọdịnaala, onye o bụla naehubere ya isi. o bụrị eziokwu na ha nwere usoro ha si elebara ya anya n'ọchịchị iji hụ na ọ naghị achị ọchịchị nchigbu, mana ọanaeze kwenyere na ya, na-ekwenyekwa n'atụmatụ ya na ndị otu ơrụ ya tụpụtara. Ihe nke a gosịrị bụ na usoro ọchịchị ọdịnaala ha zuuru ha, ma dị kwa ha mma. Usoro ọchịchị ndị Igbo bụ ọchịchị ọha, ọ bụghị ọchịchị otu onye. A na-abịakọta ọnụ tụọ arọ, ọ bụrụ na enweghị nkwekọrịta a gaghị eme ihe a chọrọ ime. Ha kwenyere na gidigidi bụ ugwu eze. Kwenye na otu osisi adị eme ọịa. Ihe ọ pụtara bụ na ndị Igbo a naghị anọ n'okpuru otu onye ọchịchị ikikere niile dị n'aka. A ga-asịkwa na ha nabatara usoro ọchịchị ha n'ihi na o sokwa n'ihe ka jikọọ ha ọnụ ruo taa.

N'ịga n'ihu usoro ọchịchị Naijirịa bụ ọchịchị onye kwue uche ya. Nke a bụ ebe ọchịchịc kwesịị ịdị n'aka ndị a na-achị achị mana ọ bụchazịghị ka e si chee ka ihe si kwụrụ ugbu a n'ala Naịjirịa. Nsogbu dị iche iche na-emekpa ọhanaeze ahụ ugbu a. Ụfọdụ mpaghara na-ekwusi ike na ha chọrọ isi n'ala Naijirịa kewapụ onwe ha. ụdị ọnọdụ a ga-eme ka ahụhụ niile a tara maka ime ka ala a bụrụ otu bụrụzịa ihe efu. N'ihi nke a o ga-aka mma ka a hapụ agbụrụ atọ kacha pụta ihe n'ala Naijjirịa ka ha bagidesie usoro ọchịchị ọdịnaala 
Isidienu: Ezi Agamniihu na Mmepe Tọrọ Atọ: Ntụle Usoro Ọchịchị Agbụrụ atọ ...

ha ike. A ga-eme nke a site n'iwepụ ọchịchị n'etiti, mee ka ikikere ọchịchị ka dị ire n’aka agbụrụ ọ bụla.

Ha ga na-elekọta ndị niile nọ n'agbụrụ ha, na-ahụkwa maka mkpa ha. Ha ga na-ewegara onye nọ n'ogo isiala ka ihe si aga n'agbụrụ ha. Ọ ga na-enyekwa ha mgbasi ma na-atụnyewkara ha arọ ga na-enyere ha aka. ụdị ọnọu dị etu a ga-eme ka mmepe bata n'agbụrụ ọ bụla karịa ka ọ dị ugbu a. Agbụrụ ọ bụla maara onwe ha nke ọma ma marakwa ihe kacha bụrụ mkpa ha. Site n'ụzọ dị etu a agamniihu tọrọ atọ ga-ehibe oche eze n'ala Naịjirịa.

\section{Mmechi}

Ezi usoro ọchịchị dị nnukwu mkpa n'obodo ọ bụla chọrọ mmepe na agammihu. Ndị Hausa nwere usoro ọchịchị pụrụ iche ha na-agbaso, ebe ikikere niile dị n'aka Emir. Usoro ọchịchị ha bụkwa nke jikọrọ ha ọụ. Ha na-ehubekwara eze ha isi ruo taa ma na-enyekwa ya ugwu na nsọpụrụ. Ndị Yoruba weere ọba dị ka eze ha na-anụrụ okwu na-enyekwa ugwu na nsọpụrụ. Ọ bụrịi eziokwu na ha naelebara ya anya n'ọchịchị n'ihi na ha anaghị akwado ọchịchị nchigbu, ma nke a emeghị ka ha ghara ijikọ ọnụ bụrụ otu. Ndị Igbo n'otu aka ahụ enweghị eze odịnaala na-achị ala Igbo niile. Usoro ọchịchị ha bụ nke onye ọ bụla bụ eze na be ya, n'ihi ya ọnụ na-eru onye ọ bụla n'okwu.

Ebe usoro ọchịchị Naịjirịa na-agbaso usoro onye kwue uche ya ma ghara ịdị na-emejupụta ebumnobi usoro e ji guzobe ya; ọ gaaka mma ka enye ndị Igbo, Hausa na Yoruba ikikere iji usoro ọchịchị ọdịnaala ha chịwa onwe ha. Nke a ga-eme ka ikikere ọchịchị gọmenti etiti belata ka mmepe dị egwu na agammihu tọrọ atọ wee bata n'obodo anyị, ebe nsogbu dị iche iche na-echu ọhanaeze ụra gaabụzị akụkọ mgbe ochie.

*Ifeyinwa Cordelia Isidienu, PhD, Department of Igbo African and Asian Studies, Nnamdi Azikiwe University, Awka

ifyisidienu@gmail.com 


\section{References}

Akinyele, R. T. (1997). "The Growth of Nationalism and the Political Evolution of Nigeria". In Osuntokun, A. and Olukoju, A. Nigerian Peoples and Cultures. Lagos: Cover Design.

Anọzie, C.C. (2003). Igbo Kwenu. Enugu: Computer Edge Publishers.

Chidili, B. (2012). "African Traditional Values and Sustenance of Democracy". In Ezenweke, E.O. \& Kanu, I.A. Issues in African Traditional Religion and Philosophy. Jos: Augustinian Publications.

Crowder, M. (1978). The Story of Nigeria. London: Faber and Faber. Deji, A.M. (2013). "Historical Background of Nigerian Politics, 1900 - 1960". IOSR Journal of Humanities and Social Science (IOSR-JHSS) vol. 16, Issue 2, pp. 84 - 94. www.losrjournals.org.

Ekwealor, C.C. (1998). Omenala na Ewumewu Ndi Igbo. Onitsha: Palma Publishers.

Emeka, L.N. (2004). "Culture, Contact, Social Change, Ethnicity, and Integration". In Okafor, R.C. and Emeka, L.N. Nigerian peoples and Culture. Enugu: New Generation Books.

Ezeigbo, A.T. (2013). "The Humanities and the Challenges of National Development in a Philitine Age". In Nwadialo et al., The Humanities and National Building. Awka: Fab Anieh.

Isidienu, I.C. (2013). "The Role of Culture in Policy Implementation and Nation Building". In Nwadialor, $\mathrm{K}$. et al., The Humanities and Nation Building. Awka: Fab Anieh.

Isidienu, I.C. (2016). "Igbo Political Organization and Impurity". In Oguejiofor, J.O., Adirika, B.N. et al. Mgbakoigba Journal of African Studies. Onitsha: New Life Press.

Okafor, R.C. and Emeka, L. (2004). "Some Traditions and Culture Areas of Nigeria". In Okafor, R.C. and Emeka, L.N. Nigerian Peoples and Culture. Enugu: New Generation Books.

Okodo, I. (2016). "The Igbo Traditional Polity as the Bedrock of Nigeria Democracy". In Arts \& Humanities. 
Isidienu: Ezi Agamniihu na Mmepe Tọrọ Atọ: Ntụle Usoro Ọchịchị Agbụrụ atọ ...

Salami, Y.K. (2006). "The Democratic Structure of Yoruba Political-Cultural Heritage". In The Journal of Pan African Studies, Vol. 1., No. 6. htts://www.academia.edu.

Tamuno, T.N. (1970). "Separatist Agitations in Nigeria Since 1914”. Journal of Modern African Studies, Vol. 8, No. 4. 